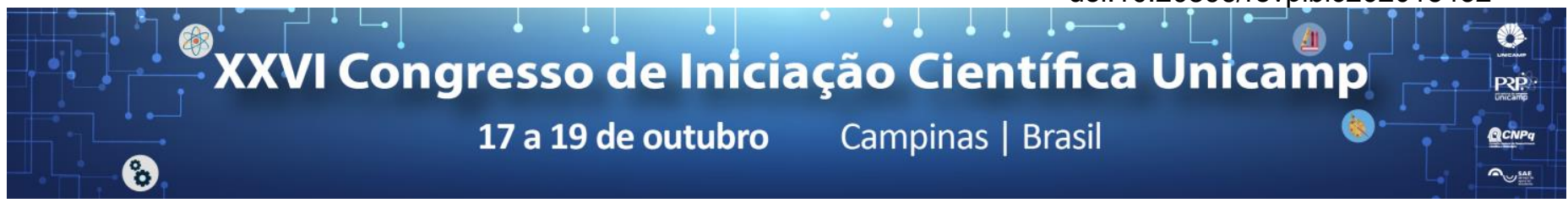

\title{
Avaliação metalômica do soro sanguíneo de pacientes com transtorno bipolar, transtorno esquizoafetivo e esquizofrenia
}

\section{Fernanda M. Casanova, Katherine C. Madrid, Marco A. Z. Arruda, Alessandra Sussulini}

\section{Resumo}

O presente trabalho consistiu na obtenção e avaliação do perfil metalômico de amostras de soro sanguíneo dos grupos denominados Controle, composto por indivíduos saudáveis, Transtorno Bipolar, por pacientes diagnosticados com transtorno bipolar tipo I, e Outras Doenças, por pacientes diagnosticados com esquizofrenia ou transtorno esquizoafetivo. Analisou-se, portanto, a presença de íons metálicos nas amostras tanto qualitativamente quanto quantitativamente, com a finalidade de observar diferenciações entre os grupos investigados, bem como de revelar possíveis marcadores biológicos do transtorno bipolar e da esquizofrenia.

\section{Palavras-chave:}

Metalômica, transtorno bipolar, esquizofrenia.

\section{Introdução}

O transtorno bipolar é uma doença mental caracterizada pela alternância de humor, com episódios de depressão e de mania, além de períodos assintomáticos ${ }^{1}$. Já a esquizofrenia apresenta uma perda de contato com a realidade e, dentre os principais sintomas, constam psicoses, alucinações e distúrbios cognitivos $^{2}$. Por fim, o transtorno esquizoafetivo pode ser considerado como uma doença transitória, pois seu diagnóstico apresenta pouca estabilidade, representando uma linha tênue que separa a esquizofrenia e o transtorno bipolar ${ }^{3}$.

Estas doenças são diagnosticadas clinicamente, ou seja, com base no quadro sintomatológico do paciente e sem algum teste bioquímico. Consequentemente, o número de diagnósticos falsos é alto, o que instiga ainda mais a busca por fatores bioquímicos que possam identificar melhor cada patologia.

À vista disso, visou-se estudar os íons metálicos presentes nas amostras de soro sanguíneo de pacientes que possuem transtorno bipolar, esquizofrenia e transtorno esquizoafetivo, além de indivíduos saudáveis, utilizando-se da estratégia metalômica para buscar relações entre os metais e as doenças. Pretendeu-se também revelar possíveis marcadores biológicos destas doenças, de modo a contribuir para posteriores estudos a respeito de testes bioquímicos para as três doenças investigadas.

\section{Resultados e Discussão}

Os compostos orgânicos presentes nas amostras de soro sanguíneo foram decompostos com o auxílio de radiação micro-ondas. Em seguida, os analitos das amostras foram atomizados, separados e analisados por espectrometria de massas com fonte de plasma indutivamente acoplado (ICP-MS). Por fim, os dados foram tratados estatisticamente com as abordagens de PCA (Principal Component Analysis) e PLS-DA (Partial Least Squares - Discriminant Analysis).

Primeiramente realizou-se uma análise qualitativa global, a qual envolveu o tratamento por PCA e PLS-DA das intensidades de 71 metais encontrados nas amostras de soro sanguíneo. A Figura 1 apresenta os agrupamentos obtidos. a)

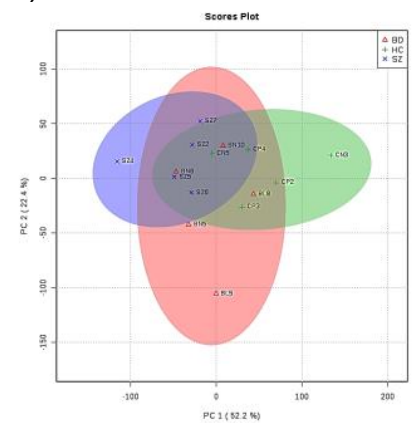

Figura 1. Scores plot 2D dos grupos Controle (HC), Transtorno Bipolar (BD) e Outras Doenças (SZ) por: a) PCA; b) PLS-DA.

Além disso, foi possível identificar os íons metálicos responsáveis pelos agrupamentos obtidos. São estes: cálcio, potássio, magnésio, cobre, alumínio, zinco, fósforo, ferro e titânio. Alguns destes tiveram suas concentrações determinadas, explorando também quantitativamente as diferenças entre as doenças.

\section{Conclusões}

Por meio de uma análise qualitativa global, concluiu-se que os perfis metalômicos dos grupos Transtorno Bipolar e Outras Doenças apresentaram maior similaridade entre si, enquanto que o grupo Controle se diferenciou melhor.

Por fim, mensurou-se as concentrações de potássio, magnésio, cobre, ferro e zinco em cada grupo.

\section{Agradecimentos}

Agradeço à orientadora Profa. Alessandra Sussulini pela oportunidade concedida a mim, à Katherine Madrid pelo auxílio durante os experimentos, ao laboratório GEPAM por disponibilizar o local para os experimentos e ao CNPq pelo suporte financeiro.

\footnotetext{
${ }^{1}$ Almeida, K. M.; Avaliação de personalidade em transtorno afetivo bipolar por meio do estudo de pares de irmãos. Tese (Doutorado) - Universidade de São Paulo 2010.

2 Souza, D. M. et al.; Proteomic approaches to unravel the complexity of schizophrenia. Expert Rev. Proteomics 2012, 97-108.

${ }^{3}$ Quarantini, L. C. et al.; Tratamento do transtorno esquizoafetivo. Revista de Psiquiatria Clínica 32(1) 2005, 89-97.
} 